\title{
Comparison of soil microbial communities between high and low yield organically managed orchards
}

\author{
Wuren Huang ${ }^{1,2}$, Qing Hu${ }^{1}$, Qiang Zhang ${ }^{3}$, Qinping Wei ${ }^{3}$, Hongyan Qi $^{1}$, Guoqiang Zhuang ${ }^{1}$, \\ Hongxun Zhang ${ }^{1}$ and Zhihui Bai ${ }^{1 *}$
}

\author{
${ }^{1}$ Research Center for Eco-Environmental Sciences, Chinese Academy of Sciences, Beijing 100085, China. \\ ${ }^{2}$ Institute for Environment and plant protection, Chinese Academy of Tropical Agriculture Sciences, Danzhou 571737, \\ China. \\ ${ }^{3}$ Institute of Forestry and Pomology, Beijing Academy of Agriculture and Forestry Sciences, Beijing 100088, China.
}

Accepted 17 May, 2012

\begin{abstract}
Microbial communities play an important role in soil nutrient cycling. The present study aimed to evaluate the relationships of plant species, soil physical and chemical properties and microbial communities between high- and low-yield organically managed fruit orchards. The Biolog ${ }^{\mathrm{TM}}$ and phospholipid fatty acids (PLFAs) analysis were used to evaluate soil microbial communities for eight typical organic orchards in Beijing, China. These included high- and low-yield agricultural sites for four types of fruit orchards: pear, peach, apple and grape. The soil properties including soil organic matter $(\mathrm{OM})$, soil $\mathrm{pH}$, soil total nitrogen (TN), soil available phosphorus (AP), soil available K (AK), cation exchange capacity (CEC), soil bulk density, soil porosity, microbial biomass and microbial activities were investigated. There were significant higher microbial biomass and lower bulk density in the soils of high-yield orchards than that in low-yield orchards. Differences between the paired soils of high- and low-yield orchards were highly associated with the average well colour development and total PLFAs.
\end{abstract}

Key words: Microbial community, biolog, substrate utilisation, phospholipid fatty acid, organic agriculture.

\section{INTRODUCTION}

Organic agriculture is an ecological production management system that promotes and enhances soil biodiversity, biological cycles and biological activity. It is based on minimal use of off-farm inputs and on management practices that restore, maintain and enhance ecological harmony. The primary goal of organic agriculture is to optimise the health and productivity of interdependent communities of soil microbes, plants, animals and people. This method avoids the use of synthetic chemical fertilisers and genetically modified organisms to influence the growth of crops, and emphasises environmental protection, animal welfare, food quality and health, sustainable resource use and social justice objectives (Goewie, 2003). Organic agriculture gives priority to long-term ecological health, such as biodiversity and soil quality, rather than shortterm productivity gains. In comparison, conventional farming utilises large quantities of inputs in the form of synthetic fertilisers, pesticide, labour and capital to improve food and fibre productivity to meet the current human demand, leading to a number of markedly undesi-rable side-effects such as environmental damage and degradation of several ecosystem services (Goewie, 2003). Problems arising from conventional practices have led to the development and promotion of organic farming systems that account the environment and public health as main concerns, and are recognised as environmental friendly production systems. In recent years, organic agriculture has gained worldwide acceptance and has deve- 
loped rapidly, at an annual rate of approximately $20 \%$ in the last decade and now accounting for $>32.2$ million ha worldwide.

Organic farming has been shown to improve many environmental and human components of the agroecosystem. However, it is clear that organic yields are usually lower, with the extent depending on the crop (Trewavas, 2004). So that organic agriculture cannot meet the increased demand for food and hence cannot be considered a sustainable form of farming for the future (Anifowoshe, 1990). The major challenge of organic farming systems is to maintain high yields and excellent quality by utilising farming practices that have acceptable in terms of environmental impacts (Murphy et al., 2007). There are relatively sudden heavy requirements for nitrate to produce leaf protein for chloroplasts and photosynthesis during plant growth and therefore maximal crop yields are likely only when the provision of soil nitrate and the associated crop requirements for leaf production are synchronised. This temporally uneven requirement for $\mathrm{N}$ in spring can only be matched by careful application of soluble chemical fertilisers. However, organic material is only slowly degraded over many months or even years and cannot release minerals in the short intense burst required for plant growth (Trewavas, 2004). Maintaining soil fertility is important for keeping high soil productivity in organic agriculture. Soil fertility in organic farming systems is based on the fixation of atmospheric nitrogen (N2), combined with recycling of nutrients via bulky organic materials, such as farmyard manure and crop residues, with only limited inputs of permitted fertilisers (Gosling and Shepherd, 2005; Nguyen et al., 1995). Plant nutriaents in organic farming are usually released slowly and are highly dependent on the mineralisation processes that make nutrients available to plants (van Delden, 2001).

The primary source of mineral nutrients for plants is the decomposition of organic matter by soil microbes (Hamilton and Frank, 2001). Microbial communities are responsible for a vast number of functions of agricultural soils. Microorganisms are key players in the mineralisation of $\mathrm{N}$, phosphorus and sulphur, which are vitally important for plant nutrition and contribute significantly to the formation of soil aggregates (Esperschutz et al., 2007). Soil microbial biomass generally comprises about $2-3 \%$ of the total organic carbon in the soil, and is recognised as an important source of nutrients due to its fast turnover. A strong positive correlation has been found between the amount of nutrients held in the microbial biomass and the amount of mineralisable nutrients in soil (Marumoto et al., 1982), indicating that nutrient cycling is tightly linked to the turnover of microbial biomass. Soil microbial community and their activities, therefore, play a key role in maintaining soil fertility and should receive attention in studies on the direct effects of crop or soil management practices.

The fruit orchard production system can be considered as a complex and interacting system consisting of soil, plants and environment. Soil fertility is vital to crop yield, and is defined as the ability of a soil to provide the conditions required for plant growth. Soil microbial communities are important for the functioning of the ecosystem, both in relation to direct interactions with plants and with regard to nutrient and organic matter cycling. Soil microbial community is positive correlated with soil quality and soil fertility. Strategies to control the microbial community associated with plant growth systems need to be based on a fundamental understanding of the factors which structure and regulate the community (Garland, 1994).

In this paper, we attempted to evaluate the relationship among soil physical and chemical properties, fruit yields and soil microbial communities in high- and low-yield organic fruit orchards. Substrate utilisation assay was used to analyse the heterotrophic microbial communities (Garland and Mills, 1991; Buyer et al., 2002), and phospholipid fatty acids (PLFAs) analysis was used to examine the overall microbial community structure, independent of culturability of the microorganisms.

\section{MATERIALS AND METHODS}

\section{Soil sample}

The soils were originally sampled in eight organic orchards for planting apple (Malus domestica), pear (Pyrus sp.), peach (Prunus persica) and grape (Vitis sp.) at an agricultural experiment station of Beijing, in northeast China. These four fruits were the most important fruits grown within the temperate zonobiome of China. Locations of the samples were determined using a GPS. The soils were sampled from high- and low-yield of the four fruits orchards respecttively. All samples assayed in this report were collected using the same collection method. Soil samples were taken from the top 20 $\mathrm{cm}$ of the soil using a $2.5 \mathrm{~cm}$ diameter auger. Every single soil sample was taken from eight cores, then well mixed and sieved $(2 \mathrm{~mm}$ mesh), and all samples were sub-sampled from these bulk soils. The sub-samples were immediately dispatched in cooled containers. The soil samples were refrigerated during preparation for analyses.

\section{Chemical and physical analyses of soils}

Soil samples were submitted to the Institute of Forestry and Pomology, Beijing Academy of Agriculture and Forestry Sciences for the following analyses: Soil organic matter $(\mathrm{OM})$, soil $\mathrm{pH}$, total soil nitrogen (TN), available soil phosphorus (AP), available soil $\mathrm{K}$ (AK), cation exchange capacity (CEC), soil bulk density and soil porosity. The soil properties were determined according to standard methods as follows: Soil $\mathrm{pH}$ was measured by a combination glass electrode (soil: water $=1: 2.5$ ). Total nitrogen was determined using Kjeldahl digestion method, and soil OM was determined using dichromate oxidation method. AP analysis was done using the method of Olsen and Sommers (1982), TN measured using alkaline hydrolysis diffusion method, and the available soil potassium (AK) was measured by the neutral ammonium acetate extraction method. CEC was measured by ammonium acetate method, and soil bulk density determined by cutting-ring method (Lu, 2000).

\section{Soil microbial community analysis}

\section{Community level physiological profiling}

Community-level physiological profiles (CLPP) were assessed using Biolog ${ }^{\mathrm{TM}}$ EcoPlate (Biolog, Hayward, California, USA). The 
EcoPlate microplates were used to analyse substrate utilisation patterns of soil microbial communities in these experiments, and performed according to Campbell et al. (1997). Briefly, a $100 \mathrm{ml}$ soil suspension was generated from an original $10 \mathrm{~g}$ aliquot (dry-weight equivalent) in $0.87 \% \mathrm{NaCl}$ solution, thus achieving a $10^{-1}$ dilution. This solution was vigorously shaken for $10 \mathrm{~min}$ on a shaker at 200 rpm for $20 \mathrm{~min}$. Ten-fold serial dilutions were made and $150 \mu \mathrm{l}$ of the $10^{-3}$ dilution solutions of each soil sample were transferred into each well of a Biolog microtiter plate. The plates were incubated at $25^{\circ} \mathrm{C}$ in darkness and measured optical densities (OD) at $590 \mathrm{~nm}$ every $24 \mathrm{~h}$ for $7 \mathrm{~d}$ using an Emax precision microplate reader (Campbell et al., 1997). Raw OD data are corrected by blanking each response well against its own first reading (immediately after inoculation). Values of the respective control-well were subtracted. The negative values that occasionally resulted were set to zero. According to the Biolog data sheet, the net absorbances at 0 and $168 \mathrm{~h}$ were the data chosen for statistical analysis. The rate of average well colour development (AWCD) was calculated from each plate at each reading time. The Shannon diversity index $\left(H^{\prime}\right)$ was calculated from the following equation:

$H^{\prime}=-\sum_{i=1}^{s} p i \ln p i$
$\mathrm{Pi}=(\mathrm{C}-\mathrm{R}) / \sum(\mathrm{C}-\mathrm{R})$

$R$ is the OD of the control well, and $S$ is the number of substrates, $p i$ is the ratio of the corrected absorbance value of each well to the sum of absorbance value of all wells. Evenness $(E)$ was calculated as: $E=H^{\prime} / H_{\max }=H^{\prime} / \mathrm{n} S$, where $H_{\max }$ is the maximum value of $H^{\prime}$, and $S$ is the number of substrates (Khalil et al., 2001).

\section{PFLAs analysis}

Microbial community structure was assessed by PLFAs analysis. Lipid extraction and PLFAs analysis were performed following the Frostegård method with minor modifications (Frostegård et al., 1993; Bååth and Anderson, 2003). Briefly, the soil was extracted in a single-phase mixture consisting of chloroform, methanol and citrate buffer $(1: 2: 0.8 \mathrm{v} / \mathrm{v} / \mathrm{v})$. After splitting the extracts into two phases by adding chloroform and buffer, the lipid-containing phase was dried under a stream of Nitrogen. The lipid materials were fractionated on silicic acid column into neutral lipids, glycolipids and polar lipids (phospholipids). The phospholipids were transesterified by a mildalkaline methanolysis and the resulting fatty acid methyl esters were analysed using a gas chromatography-mass spectroscopy (GC-MS) system (Hewlett Packard HP 6890) equipped with an HP5 capillary column $(60 \mathrm{~m} \times 0.32 \mathrm{~mm})$, and the mole fraction of each component was calculated. Methyl nonadecanoate fatty acid (19:0) was used as the internal standard. The fatty acid nomenclature chosen for this study was described by Frostegård et al. (1993). The sum of the following PLFAs was used a measure of the bacterial biomass: i14:0, i15:0, a15:0, 15:0, i16:0, 10Me16:0, i17:0,

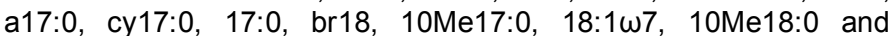
cy19:0 (Frostegård and Bååth, 1996). The PLFA 18:2w6,9 was taken to indicate predominantly fungal biomass (Klamer and Bååth, 2004). Ratios of Gram-positive to Gram-negative bacteria were calculated by taking the sum of the predominant Gram-positive PLFAs 16:0(10Me), 17:0(10Me), 18:0(10Me), i15:0, a15:0, i16:0, i17:0, and a17:0 divided by the sum of the predominant Gram-

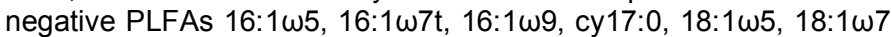
and cy 19:0 (Yao et al., 2000). A ratio of the fungal/bacterial PLFAs was used as a biomass index to indicate the changes in the ratio of fungal to bacterial biomass. Total PLFAs concentration was used as an index of the total viable microbial biomass.

\section{Statistical analysis}

All ANOVA, regression and multivariate analyses were conducted using the statistical program SPSS 16.0. Means and least significant differences were calculated using one-way ANOVA.

\section{RESULTS}

\section{Physical-chemical characteristics of soil samples}

The land geographical location and physical-chemical characteristics of soil samples are shown in Table 1. Soil $\mathrm{pH}$ was weakly alkaline with range 7.55-8.49. The highest levels of available phosphorus (AP) and soil available (AK) were in the soil samples of the high-yield apple orchard: 261.0 and $202.0 \mathrm{mg} / \mathrm{kg}$, respectively. The lowest AP $(23.1 \mathrm{mg} / \mathrm{kg})$ and the lowest AK $(111.6 \mathrm{mg} / \mathrm{kg})$ contents were in the low-yield and high-yield pear orchards, respectively. Soil OM, TN, AK and AP were higher in the high-yield orchards of apple and grape than in the pair site low-yield orchards. Whereas, in pear and peach orchards, the contents of soil TN, OM and AK were lower in high-yield than low-yield orchards. The soil bulk density in high-yield was lower than in low-yield orchards for the four types of fruit. The CEC in grape and peach orchards was higher in high-yield than low-yield orchards; in contrast, CEC was lower in apple and pear high-yield compared to low-yield orchards.

\section{CLPP}

\section{Biolog carbon substrate metabolic activities}

The carbon substrate metabolic activities of soils from the high-yield and low-yield orchards of four kinds of fruit were measured by AWCD (Figure 1), calculated from each sample's incubation time period. AWCD of Biolog EcoPlates is an important index for evaluating diversity of soil microbial biomass function. The values represent the changes in soil bacterial community activity in utilising the catabolic diversity in different treatments. AWCD increased rapidly after $48 \mathrm{~h}$. AWCD in the soil of the high-yield were consistently higher than in low-yield orchards for the four types of fruit trees. This indicated that soil in the highyield orchard had higher soil bacterial activity in utilising catabolic diversity. The soil microbial communities under the low-yield orchards used fewer carbon substrates and had lower metabolic activity than that of high-yield orchards. The OD data at $590 \mathrm{~nm}$ for six kinds of carbon sources indicated that soil microbial populations in different fruit orchard can vary tremendously.

The lowest utilisations for the metabolism of amines/ amides, amino acids, carbohydrates, carboxylic acids, miscellaneous and polymers (Figure 2) were associated with the soil of the low-yield grape orchard. However, carbohydrates and miscellaneous had OD significantly greater in low-yield than high-yield grape orchards (Figure 2). For soil of peach orchards, the highest OD was in the amino acids utilisation of high-yield peach orchards. The utilisation of carbon substrates was higher 
Table 1. Physical and chemical properties of soils, the standard deviation of the mean is given in brackets.

\begin{tabular}{|c|c|c|c|c|c|c|c|c|}
\hline \multirow[b]{2}{*}{ Soil type } & \multirow[b]{2}{*}{$\begin{array}{l}\text { Geographical } \\
\text { location }\end{array}$} & \multicolumn{7}{|c|}{ Soil property } \\
\hline & & $\begin{array}{c}\text { Soil bulk density } \\
(\mathrm{g} / \mathrm{ml})\end{array}$ & TN (g/kg) & $\operatorname{SOM}(g / k g)$ & AP $(\mathrm{mg} / \mathrm{kg})$ & AK (mg/kg) & CEC (mmol/kg) & Soil pH \\
\hline High-yield apple & \multirow{2}{*}{$116.20^{\circ} \mathrm{E} 40.22^{\circ} \mathrm{N}$} & $1.52(0.10)$ & $1.09(0.06)$ & $18.8(1.31)$ & $202.0(33.15)$ & $261.0(23.64)$ & $187(8.19)$ & $7.62(0.47)$ \\
\hline Low-yield apple & & $1.53(0.08)$ & $0.79(0.34)$ & $15.9(5.45)$ & $110.2(40.55)$ & $187.3(42.25)$ & $209(6.08)$ & $7.55(0.15)$ \\
\hline High-yield grape & \multirow{2}{*}{$116.67^{\circ} \mathrm{E} 39.92^{\circ} \mathrm{N}$} & $1.10(0.28)$ & $1.38(0.52)$ & $22.9(0.90)$ & 73.5 (12.95) & 190.7 (46.29) & $211.3(4.5)$ & $8.00(0.27)$ \\
\hline Low-yield grape & & $1.57(0.06)$ & $0.99(0.16)$ & $18.2(2.30)$ & $81.6(2.50)$ & $133.0(8.89)$ & $181.7(8.62)$ & $8.36(0.05)$ \\
\hline High-yield pear & \multirow{2}{*}{$116.33^{\circ} \mathrm{E} 39.73^{\circ} \mathrm{N}$} & $1.49(0.02)$ & $0.49(0.10)$ & $8.13(1.42)$ & $66.5(31.01)$ & $111.6(13.76)$ & $79.5(10.11)$ & $8.49(0.19)$ \\
\hline Low-yield pear & & $1.53(0.05)$ & $0.81(0.06)$ & $14.8(1.35)$ & $23.1(12.54)$ & 120.7 (28.02) & $165.0(21.0)$ & $8.21(0.08)$ \\
\hline High-yield peach & \multirow{2}{*}{$117.10^{\circ} \mathrm{E} 40.13^{\circ} \mathrm{N}$} & $1.23(0.06)$ & $1.14(0.08)$ & 16.9 (1.82) & $28.1(22.44)$ & $177.3(27.30)$ & 242.3 (13.32) & $8.09(0.13)$ \\
\hline Low-yield peach & & $1.47(0.01)$ & $1.18(0.21)$ & $21.7(2.05)$ & $62.9(13.60)$ & $244.0(29.5)$ & $242(17.1)$ & $8.00(0.03)$ \\
\hline
\end{tabular}

in high-yield than low-yield peach orchards, except for miscellaneous. For pear orchards, the utilisation of carbon substrates was higher in high-yield than low-yield orchards, except for polymers. For apple orchards, the utilisation of carbon substrates in high-yield was all higher than that in lowyield orchards.

\section{Metabolic diversity}

The diversity indexes were used to represent the level of the utilisation of carbon resources by the soil microbial community. The Shannon-Wiener index $(\mathrm{H})$ and Simpson's diversity index suggested a diversity of carbon substrates were utilised by soil microbial communities in the orchards (Table 2). The soils exhibited slight differences between the high-yield and low-yield orchards. The Shannon-Wiener $(\mathrm{H})$ and Simpson's diversity index were higher in high-yield than low-yield orchards, except for pear orchards. The evenness index had the same trend as the Shannon-Wiener index.

\section{PLFAs analysis of microbial communities}

The PLFAs are major cell membrane constituents. Different subsets of microbial community shown different PLFAs patterns, and since PLFAs could be degraded rapidly upon cell death, they were good indicators of living organisms.

We investigated the soil microbial communities in the soils of high- and low-yield orchards by analysing the composition of the PLFAs (Table 3). The total PLFAs content showed great variation among the fruit orchards, with range 9.3-47.6 $\mathrm{nmol} \mathrm{g}{ }^{-1}$ dry soil. The highest total PLFAs concentration was in the soils of the high-yield grape orchard $\left(47.6 \mathrm{nmol} \mathrm{g}{ }^{-1}\right.$ dry soil); the second highest concentration was in the soils of the highyield apple orchard $\left(46.7 \mathrm{nmol} \mathrm{g}^{-1}\right.$ dry soil). The lowest total PLFAs content was in soils of the lowyield peach orchard $\left(9.3 \mathrm{nmol} \mathrm{g}^{-1}\right.$ dry soil); the second lowest was in the low-yield pear orchard $\left(18.8 \mathrm{nmol} \mathrm{g}^{-1}\right.$ dry soil). The total PLFAs content in high-yield orchards was always significantly higher than the corresponding low-yield fruit orchards. There were differences in bacterial biomass (esti- mated by PLFAs content) between high-and lowyield orchards. The total bacterial PLFAs content was significantly higher in the high-yield than lowyield orchards of peach, apple and grape. Grampositive bacteria showed the same trend as bacterial biomass, that is, more abundant in high-yield orchards of peach, grape and apple than in lowyield orchards; however, abundance was greater for the low-yield pear compared to the high-yield pear orchard. Gram-negative bacteria were more abundant in high-yield orchards of all fruit types compared to low-yield orchards. High-yield orchards of all fruit types had lower GP/GN ratios compared to the corresponding low-yield orchards. The amount of fungal PLFAs was higher in the highyield than the low-yield orchards of the four types of fruit trees. The high-yield orchards had higher fungi/bacteria ratios than low-yield orchards of peach, pear and grape, but not for apples.

\section{DISCUSSION}

Soil is an important natural resource and medium for plant growth, its quality is crucial for sustaining 

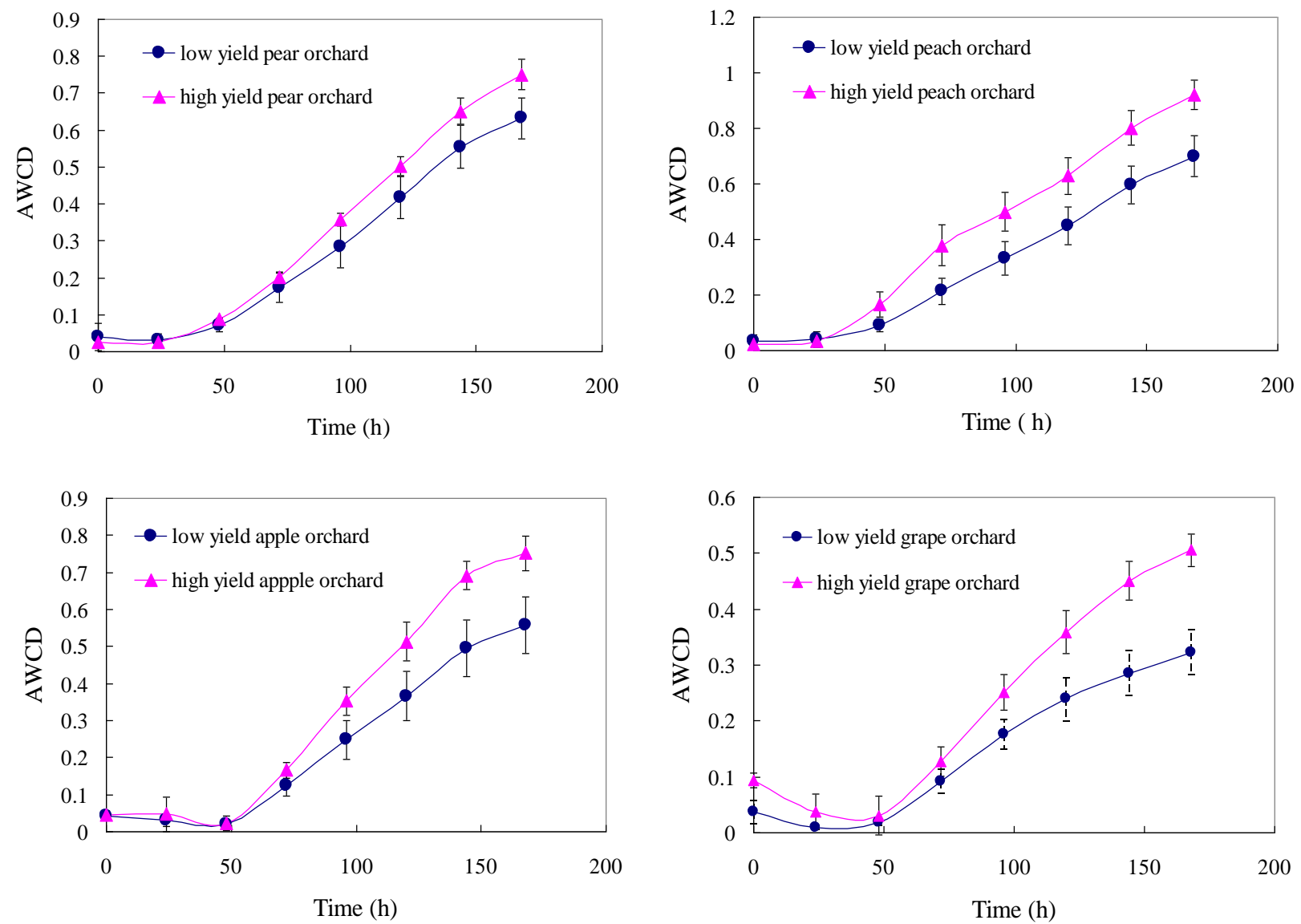

Figure 1. Substrate utilisation patterns on soils from four different fruit trees between high-yield and low-yield orchard of soil microbial communities as indicated by AWCD at $590 \mathrm{~nm}$.

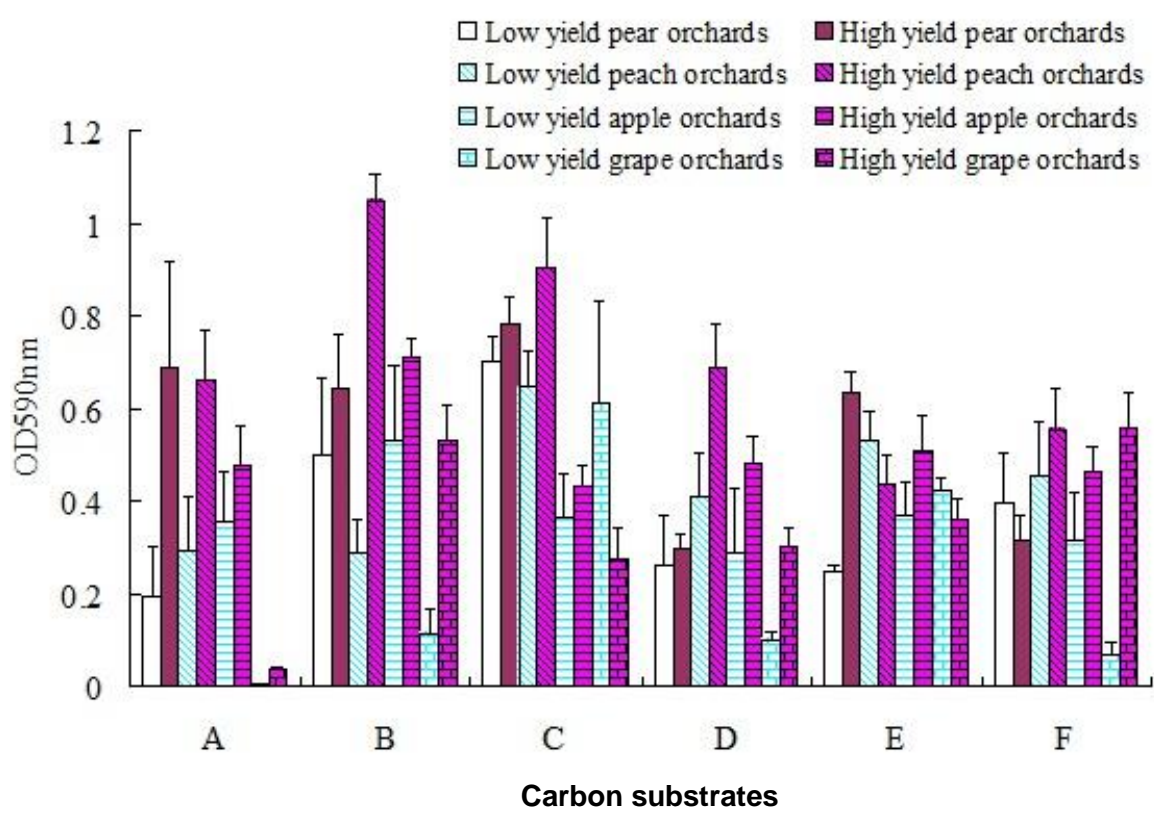

Figure 2. Average utilisations of different carbon substrates by soil microorganisms in the high-yield and low-yield orchards in four kinds of fruit orchards based on $120 \mathrm{~h}$ incubations. A-F denotes amines/amides, amino acids, carbohydrates, carboxylic acids, miscellaneous and polymers, respectively. 
Table 2. Diversity patterns for soils of high-yield and low-yield orchards.

\begin{tabular}{lccc}
\hline Soil type & Shannon-Wiener & Evenness & Simpson's diversity \\
\hline High-yield apple & $2.72 \pm 0.09$ & $0.85 \pm 0.03$ & $0.92 \pm 0.01$ \\
Low-yield apple & $2.27 \pm 0.63$ & $0.81 \pm 0.07$ & $0.84 \pm 0.12$ \\
High-yield grape & $2.53 \pm 0.12$ & $0.80 \pm 0.01$ & $0.88 \pm 0.01$ \\
Low-yield grape & $2.12 \pm 0.38$ & $0.78 \pm 0.06$ & $0.81 \pm 0.05$ \\
High-yield pear & $2.33 \pm 0.21$ & $0.74 \pm 0.04$ & $0.86 \pm 0.02$ \\
Low-yield pear & $2.34 \pm 0.43$ & $0.77 \pm 0.08$ & $0.85 \pm 0.07$ \\
High-yield peach & $2.79 \pm 0.25$ & $0.84 \pm 0.06$ & $0.92 \pm 0.01$ \\
Low-yield peach & $2.64 \pm 0.20$ & $0.84 \pm 0.05$ & $0.91 \pm 0.02$ \\
\hline
\end{tabular}

Table 3. Total PLFAs, PLFAs of bacteria and fungi, PLFAs of Gram-positive bacteria (GP), PLFAs of Gram-negative bacteria (GN), ratio of GP/GN, Fungi and fungi/bacteria extracted from soil of four types of fruit orchards (expressed in nmol $\mathrm{g}^{-1}$ soil). The standard deviation of the mean is given in brackets.

\begin{tabular}{lccccccc}
\hline Soil type & Bacterial & GP & GN & GP/GN & Fungi & Fungi/bacteria & Total PLFAs \\
\hline High-yield peach & $7.6(0.8)$ & $3.4(0.1)$ & $4.1(1.2)$ & $0.86(0.2)$ & $2.0(0.2)$ & $0.26(0.0)$ & $17.5(2.4)$ \\
Low-yield peach & $3.3(1.3)$ & $1.5(0.8)$ & $1.5(0.4)$ & $0.98(0.28)$ & $0.8(0.3)$ & $0.23(0.01)$ & $9.3(2.1)$ \\
High-yield pear & $10.9(0.8)$ & $3.0(0.1)$ & $7.5(0.8)$ & $0.40(0.04)$ & $2.5(0.8)$ & $0.23(0.09)$ & $22.7(1.2)$ \\
Low-yield pear & $13.1(2.7)$ & $6.1(2.7)$ & $6.7(0.4)$ & $0.91(0.36)$ & $1.0(0.1)$ & $0.08(0.01)$ & $18.8(1.1)$ \\
High-yield apple & $32.2(6.9)$ & $16.5(2.7)$ & $14.8(4.3)$ & $1.15(0.17)$ & $1.9(0.7)$ & $0.06(0.01)$ & $46.7(10.2)$ \\
Low-yield apple & $22.6(5.2)$ & $12.1(3.2)$ & $9.7(2.0)$ & $1.23(0.16)$ & $1.8(0.8)$ & $0.08(0.02)$ & $39.6(9.8)$ \\
High-yield grape & $23.96(1.0)$ & $6.7(0.3)$ & $15.8(0.8)$ & $0.42(0.00)$ & $4.9(0.2)$ & $0.20(0.00)$ & $47.6(1.6)$ \\
Low-yield grape & $9.0(3.7)$ & $3.3(0.7)$ & $5.1(2.5)$ & $0.7(0.3)$ & $0.9(0.5)$ & $0.1(0.0)$ & $14.8(6.6)$ \\
\hline
\end{tabular}

plant productivity. Soil quality is based on physical-chemical properties (e.g. bulk density, temperature, pH, CEC, organic carbon, TN, humic-like substances, AP and AK) and is useful in assessment of soil fertility. Biological parameters that indicate microbial biomass and activity are also useful as indicators of soil quality. Microbial communities are critical components of soil, and microorganisms are involved in nutrient release and organic matter decomposition. It is still unclear whether microbial organisms are correlated with fruit yield. In order to address this question, soil microbial community structure and fruit yields were investigated in field fruit-production systems and compared with SCSU patterns and PLFAs profiles. Four types of high- and low-yield fruit orchard soils were tested for soil chemical and physical properties and microbial community structures. The present experiment demonstrated that the soils of organic systems in highand low-yield orchards showed difference on microbial community and activity. On the basis of substrate utilisation patterns in soils (Figure 1), AWCD was consistently higher in soil of high-yield than low-yield orchards of the same type of fruit. AWCD indicated the overall rate of the community-level response in the Biolog plate, and infers greater metabolic functioning of the soil bacterial community in high-yield than in low-yield orchards. The diversity patterns (Shannon-Wiener and Simpson's diversity) were greater for soils of high-yield than of low-yield orchards (Table 2), indicating more abundant of microbes in soil of high-yield orchards.

The Biolog method indicates the activity of fast-growth bacteria or eutrophic bacteria only, and cannot reveal the activity of slow-growth or uncultured bacteria. Thus only a part of soil microbial characteristics were shown by this method. To fully understand soil microbial community structure, other assay methods are required. Analysis of microbial PLFAs is an effective tool for characterising microbial communities, and provides a quantitative profile of the microbial population. The PLFAs data indicate that microbial biomass was higher in high-yield compared to low-yield orchards. It has been reported that the amount of nutrients held in microbial biomass and amounts of mineralisable nutrients in the soil are positively correlated (Carter and MacLeod, 1987; Dalal and Mayer, 1987). The differences in microbial biomass may have implications for nutrient availability to crops. High microbial biomass and activity often lead to high nutrient availability to crops (Zaman et al., 1999; Tu et al., 2006). Thus we conclude that soil of high-yield orchards had higher nutrient availability than that of the low-yield orchards. The soil in relatively higher fruit-production orchards could have more microbial biomass in different type of fruit tree orchards. Higher microbial biomass was positively influenced to the fruit production, indicating that microbial biomass can be a valuable ingredient of soil.

The use of carefully identified 'paired sites' indicated some differences between paired sites for each kind of 
fruit tree. Soil bulk density was consistently greater in the low-yield than the high-yield orchards. Pankhurst (1995) reported that the soils showing yield decline had a high bulk density and low microbial biomass, indicating that there may be populations of detrimental soil organisms affecting the growth and health of the plant root system. High soil bulk density indicates soil compaction and less air in the soil (important for plant roots and microorganisms). Lower $\mathrm{pH}$ was also recorded on low-yield orchards, except for grape. But the other soil (except soil bulk density, the $\mathrm{pH}$ ) properties showed no clear trends between the high-yield and low-yield orchards and their corresponding fruit yields (Table 1). Therefore, we could attribute the higher yields of the organic orchards mainly to the higher abundant of soil microbial biomass, which can help to supply the nutrients for plant growth and development over time.

Since the abundant of soil microbial communities is closely related to the fruit yields in organic orchards, we can adjust the crop management to improve the soil microbial diversity and so ameliorate soil quality, such as, using organic amendments to increase the microbial biomass and microbial activity (Huang et al., 2011). We can also incorporate or subsequently manipulate these beneficial microbial populations in the field over the course of a growing season(s). Further studies will be performed for understanding of the mechanisms of soil microbial community promoting fruit yield.

\section{ACKNOWLEDGEMENTS}

This work was funded by the Beijing Science and Technology Program (Nos. D101105046410004 and D0706003040193), the Commonweal Project of Agricultural Special Funds (nyhyzx07-024) and the Tianjin Hi-tech Support Program Key Projects (No. 11ZCGYSF01400).

\section{REFERENCES}

Anifowoshe TO (1990). Food production -- problems and prospects. GeoJournal 20(3): 243-247.

Bååth $\mathrm{E}$, Anderson TH (2003). Comparison of soil fungal/bacterial ratios in a $\mathrm{pH}$ gradient using physiological and PLFA-based techniques. Soil Biol. Biochem. 35(7): 955-963.

Buyer JS, Roberts DP, Russek-Cohen E (2002). Soil and plant effects on microbial community structure. Can. J. Microbiol. 48(11): 955-64.

Campbell CD, Grayston SJ, Hirst DJ (1997). Use of rhizosphere carbon sources in sole carbon source tests to discriminate soil microbial communities. J. Microb. Methods 30: 33-41.

Carter MR, Macleod JA (1987) Biological properties of some Prince Edward Island soils: Relationship between microbial biomass nitrogen and mineralizable nitrogen. Can. J. Soil Sci. 67: 333-340.

Dalal RC, Mayer RJ (1987). Long-term trends in fertility of soils under continuous cultivation and cereal cropping in southern Queensland. VII. Dynamics of nitrogen mineralization potentials and microbial biomass. Aust. J. Soil Res. 25:461-472.

Esperschutz J, Gattinger A, Mader P, Schloter M, Fliessbach A (2007). Response of soil microbial biomass and community structures to conventional and organic farming systems under identical crop rotations. FEMS Microbiol. Ecol. 61: 26-37.
Frostegård A, Bååth $E$ (1996). The use of phospholipid fatty acid analysis to estimate bacterial and fungal biomass in soil. Biol. Fertil. Soils 22: $59-65$.

Frostegård A, Tunlid A, Bååth E (1993). Phospholipid fatty acid composition, biomass, and activity of microbial communities from two soil types experimentally exposed to different heavy metals. Appl. Environ. Microbiol. 59: 3605-3617.

Garland JL (1994). The structure and function of microbial communities in recirculating hydroponic systems. Adv. Space Res. 14(11): 383386.

Garland JL, Mills AL (1991). Classification and characterization of heterotrophic microbial communities on the basis of patterns of community-level sole-carbon-source utilization. Appl. Environ. Microbiol. 57: 2351-2359.

Goewie EA (2003). Organic agriculture in the Netherlands; developments and challenges. NJAS - Wageningen J. Life Sci. 50(2): 153169.

Gosling P, Shepherd M (2005). Long-term changes in soil fertility in organic arable farming systems in England, with particular reference to phosphorus and potassium. Agric. Ecosyst. Environ. 105: 425-432.

Hamilton EW, Frank DA (2001). Can plants stimulate soil microbes and their own nutrient supply? Evidence from a grazing tolerant grass. Ecology 82: 2397-2402.

Huang W, Bai Z, Hoefel D, Hu Q, Lv X, Zhuang G, Xu S, Qi H, Zhang H (2011). Effects of cotton straw amendment on soil fertility and microbial communities. Front. Environ. Sci. Eng. 6(3):336-349.

Khalil $S$, Bååth $E$, Alsanius $B$, Englund JE, Sundin $P$, Gertsson UE, Jensen $P$ (2001). A comparison of sole carbon source utilization patterns and phospholipid fatty acid profiles to detect changes in the root microflora of hydroponically grown crops. Can. J. Microbiol. 47: 302-308.

Klamer M, Bååth E (2004). Estimation of conversion factors for fungal biomass determination in compost using ergosterol and PLFA 18:2[omega]6,9. Soil Biol. Biochem. 36: 57-65

Lu RK (2000). Analytical Methods for Soil and Agricultural Chemistry (In Chinese). Beijing: China Agricultural Science and Technology Press, 13-147.

Marumoto T, Anderson JPE, Domsch KH (1982) Mineralization of nutrients from soil microbial biomass. Soil Biol. Biochem. 14: 469475.

Murphy KM, Campbell KG, Lyon SR, Jones SS (2007). Evidence of varietal adaptation to organic farming systems. Field Crops Res. 102(3): 172-177.

Nguyen ML, Haynes RJ, Goh KM (1995). Nutrient budgets and status in three pairs of conventional and alternative mixed cropping farms in Canterbury, New Zealand. Agric. Ecosyst. Environ. 52(2-3): 149-162.

Olsen SR, Sommers LE (1982). Phosphorus. In: Page AL, Miller RH, Keeney DR, Methods of soil analysis, Part 2. Chemical and microbiological properties. Madison, WI: American Society of Agronomy and Soil Science Society of America, 403-430.

Pankhurst CE, Hawke BG, McDonald HJ, Kirkby CA, Buckerfield JC, Doube BM (1995). Evaluation of soil biological properties as potential bioindicators of soil health. Aust. J. Exp. Agric. 35: 1015-1028.

Trewavas A (2004). A critical assessment of organic farming-and-food assertions with particular respect to the UK and the potential environmental benefits of no-till agriculture. Crop Prot. 23(9): 757781.

Tu C, Ristaino JB, Hu S (2006). Soil microbial biomass and activity in organic tomato farming systems: Effects of organic inputs and straw mulching, Soil Biol. Biochem., 38: 247-255

van Delden A (2001). Yield and Growth Components of Potato and Wheat under Organic Nitrogen Management. Agron. J. 93: 13701385 .

Yao H, He Z, Wilson MJ, Campbell CD (2000). Microbial biomass and community structure in a sequence of soils with increasing fertility and changing land use. Microb. Ecol. 40 (3): 223-237.

Zaman M, Di HJ, Cameron KC (1999). A field study of gross rates of $\mathrm{N}$ mineralization and nitrification and their relationships to microbial biomass and enzyme activities in soils treated with dairy effluent and ammonium fertilizer. Soil Use Manage. 15, 188-194. 